\title{
Effect of the Nature of the Counterion on the Properties of Anionic Surfactants. 5. Self-Association Behavior and Micellar Properties of Ammonium Dodecyl Sulfate
}

\author{
Celize M. Tcacenco, ${ }^{\dagger}$ Raoul Zana, ${ }^{\dagger}$ and Barney L. Bales ${ }^{*}, \dagger$ \\ Department of Physics and Astronomy, California State University at Northridge, \\ Northridge, California 91330-8268, and Institut C. Sadron, CNRS, 6 rue Boussingault, \\ 67000, Strasbourg, France
}

Received: May 14, 2005; In Final Form: June 24, 2005

\begin{abstract}
Micelles formed in water from ammonium dodecyl sulfate (AmDS) are characterized using time-resolved fluorescence quenching (TRFQ), electron paramagnetic resonance (EPR), conductivity, Krafft temperature, and density measurements. TRFQ was used to measure the aggregation number, $N$, and the quenching rate constant of pyrene by dodecylpyridinium chloride, $k_{\mathrm{Q}} . N$ depends only on the concentration $\left(C_{\mathrm{aq}}\right)$ of ammonium ions in the aqueous phase whether these counterions are derived from the surfactant alone or from the surfactant plus added ammonium chloride as follows: $N=N^{0}\left(C_{\mathrm{aq}} / \mathrm{cmc}_{0}\right)^{\gamma}$, where $N^{0}$ is the aggregation number at the critical micelle concentration in the absence of added salt, $\mathrm{cmc}_{0}$, and is equal to 77,70 , and 61 at 16,25 , and $35{ }^{\circ} \mathrm{C}$, respectively. The exponent $\gamma=0.22$ is independent of temperature in the range 16 to $35^{\circ} \mathrm{C}$. The fact that $N$ depends only on $C_{\text {aq }}$ permits the determination of the micelle ionization degree $(\alpha)$ by employing various experimental approaches to exploit a recent suggestion (J. Phys. Chem. B 2001, 105, 6798) that $N$ depends only on $C_{\mathrm{aq}}$. Utilizing various combinations of salt and surfactant, values of $\alpha$ were obtained by finding common curves as a function of $C_{\mathrm{aq}}$ of the following experimental results: the Krafft temperature, $N$, $k_{\mathrm{Q}}$, the microviscosity of the Stern layer determined from the rotational correlation time of a spin probe, 5-doxyl stearic acid methyl ester, and the spin-probe sensed hydration of the micelle surface. The values of $\alpha$, determined from applying the aggregation number-based definition of $\alpha$ to all of these quantities, were within experimental uncertainty of the values $\alpha=0.19,0.20$, and 0.21 derived from conductivity measurements at 16,25 , and $35^{\circ} \mathrm{C}$, respectively. The volume fraction of the Stern layer occupied by water decreases as $N$ increases. For AmDS micelles, both the hydration and its decrease are predicted by a simple theory of micelle hydration by fixing the parameters of the theory for sodium dodecyl sulfate and employing no further adjustable parameters. For a given value of $N$, the hydration decreases as the temperature increases.
\end{abstract}

\section{Introduction}

This paper is part of a series that deals with the effect of the nature of the counterion of anionic surfactants on their selfassociation behavior and properties of anionic micelles. ${ }^{1-4}$ Part 1 dealt mainly with the critical micellization concentration $(\mathrm{cmc})$, micelle ionization degree, $\alpha$, and micelle aggregation number, $N$, of tetramethyl-, tetraethyl-, tetrapropyl-, and tetrabutylammonium dodecyl sulfates (TMADS, TEADS, TPADS, and TBADS, respectively) and reported also some complementary measurements on sodium and cesium dodecyl sulfates (SDS and CsDS, respectively). ${ }^{1}$ In part 2, a newly developed electron paramagnetic resonance (EPR) technique ${ }^{5,6}$ was used to estimate the ionization degree of the micelles of the six surfactants. ${ }^{2}$ This method has been well tested on several ionic surfactants and shown to yield values of $\alpha$ that are in good agreement with reported values that were obtained using other methods, such as Evans' method, ${ }^{7}$ which is based on the analysis of electrical conductivity data. The EPR method was found to provide values of $\alpha$ in good agreement with those obtained using Evans' method for SDS and CsDS. However the EPR method yielded values of $\alpha$ systematically larger than Evans' $\operatorname{method}^{7}$ for the tetraalkylammonium dodecyl sulfates (TAADS). Part 3 dealt

* Address correspondence to this author. E-mail: barney.bales@csun.edu.

California State University at Northridge.

$\doteqdot$ Institut C. Sadron, CNRS. specifically with the self-association behavior of TBADS as this surfactant shows clouding and phase separation upon heating. ${ }^{3}$ Part 4 characterized TAADS micelles as reaction media. ${ }^{4}$ The micelle microviscosity was obtained from the rotational correlation times of a micelle-solubilized spin probe determined using EPR. The bimolecular reaction rate as deduced from the fluorescence quenching of pyrene by dodecylpyridinium chloride was found to conform well to a hydrodynamic description (Stokes-Einstein-Smolukhovsky equation).

No satisfactory explanation was provided for the difference in $\alpha$ values from Evans' method $^{6}$ and the EPR technique. ${ }^{2-4}$ The hydrophobic character and the large size of the tetraalkylammonium ions were discussed as possibly having an influence on the observed behavior. This aspect is further investigated here. Indeed there is a rather large difference between the largest common alkali metal ion, i.e., $\mathrm{Cs}^{+}$, and the smallest tetraalkylammonium ion, i.e., $\mathrm{TMA}^{+}$, in terms of size $(0.169$ and more than $0.3 \mathrm{~nm}$, respectively, for the dry ions) and hydrophilicity $\left(\mathrm{Cs}^{+}\right.$is more hydrophilic than $\left.\mathrm{TMA}^{+}\right)$. The ammonium ion, $\mathrm{NH}_{4}{ }^{+}$, is the only ion that stands between $\mathrm{Cs}^{+}$and $\mathrm{TMA}^{+}$, with a radius of about $0.23 \mathrm{~nm}$ (based on the length of the $\mathrm{N}-\mathrm{H}$ bond and the van der Waals radius of the hydrogen atom) and a rather hydrophilic character, if ions such as mono-, di-, and tri-methylammonium are not considered. This prompted us to synthesize the ammonium dodecyl sulfate (AmDS) and to 
undertake a full investigation of its self-association behavior. The investigations were much focused on the micelle ionization degree, which was determined using the Evans $\operatorname{method}^{7}$ (electrical conductivity measurements) and from the variations of the Krafft temperature, micelle aggregation number, intramicellar quenching rate constant, micelle microviscosity, and apparent micelle hydration (from EPR measurements) measured in the presence and absence of ammonium chloride. The present study afforded us the opportunity to collect into one work several diverse techniques that we have applied to micelles in recent years. All of the methods have been discussed in detail; therefore, we have attempted to be as brief as possible and have likewise limited the discussion.

\section{Materials and Methods}

Materials. The AmDS was prepared as follows. A solution of $10 \mathrm{~g}$ of sodium dodecyl sulfate (SDS, Merck 99\%) in about $100 \mathrm{~mL}$ of water was passed through a $20-\mathrm{cm}$ column of cationexchange resin (Merck, type 1 ion-exchanger) in the acid form. The capacity of the amount of resin in the column was in excess by a factor of about 3 with respect to the amount of SDS. The solution of dodecylsulfuric acid coming out of the column directly fell into a flask containing a $0.4 \mathrm{M}$ solution of ammonia maintained at $4{ }^{\circ} \mathrm{C}$ to minimize the release of $\mathrm{NH}_{3}$ in the room and to reduce a possible hydrolysis of the dodecylsulfuric acid. The neutralization was monitored by $\mathrm{pH}$ measurements. The neutralization point was taken as that where the $\mathrm{pH}$ dropped very abruptly from above 9 to below 4. The resulting AmDS solution was lyophilized. The elemental analysis of the solid showed that the synthesized surfactant was of high purity $(\%$ carbon found 51.01, expected 50.86; \% nitrogen found 4.98, expected 4.94 ; \% hydrogen found 10.38 , expected $10.24 ; \%$ sulfur found 11.34 , expected $11.30 ; \% \mathrm{H}_{2} \mathrm{O} 0.054$ ).

The ammonium chloride (Prolabo, minimum purity of $99.5 \%$ ) was dried at $40{ }^{\circ} \mathrm{C}$ under vacuum and in the presence of phosphorus dioxide before use.

The samples of fluorescent probe pyrene and of the pyrene fluorescence quencher dodecylpyridinium chloride ( $\mathrm{DPyCl})$ were the same as in previous investigations. ${ }^{1,3}$ The EPR probe 5-doxylstearic acid methyl ester (5DSE) was purchased from Aldrich.

Methods. The Krafft temperatures of AmDS solutions in water and water $+\mathrm{NH}_{4} \mathrm{Cl}$ were obtained visually to within 0.1 ${ }^{\circ} \mathrm{C}$ using a calibrated thermocouple. The mixture of solid AmDS and water or aqueous $\mathrm{NH}_{4} \mathrm{Cl}$ was heated at $40{ }^{\circ} \mathrm{C}$ and stirred until full solubilization of the surfactant. The solution was cooled until the surfactant precipitated, maintained so for $1-2 \mathrm{~h}$, and then slowly heated. The disappearance of the solid occurred in a very narrow range of temperature and the experiment could be repeated for a more accurate determination of the Krafft temperature.

The cmc values were obtained using the electrical conductivity method at 10,25 , and $40{ }^{\circ} \mathrm{C}$ from the plots of the specific conductivity $K$ against the surfactant concentration $C$. These plots showed a sharp change of slope. The cmc was taken as the concentration corresponding to the intercept of the two straight lines drawn through the experimental points located below and above the range of the rapid change of slope. The $K$ versus $C$ plots were used to obtain the values of the micelle ionization degree $\alpha$ using Evans $\operatorname{method}^{7}$ (see details in ref 1).

The aggregation number, $N$, of AmDS micelles was determined using time-resolved fluorescence quenching (TRFQ), with pyrene as fluorescent probe and $\mathrm{DPyCl}$ as quencher. Details concerning the preparation of the solutions and the analysis of
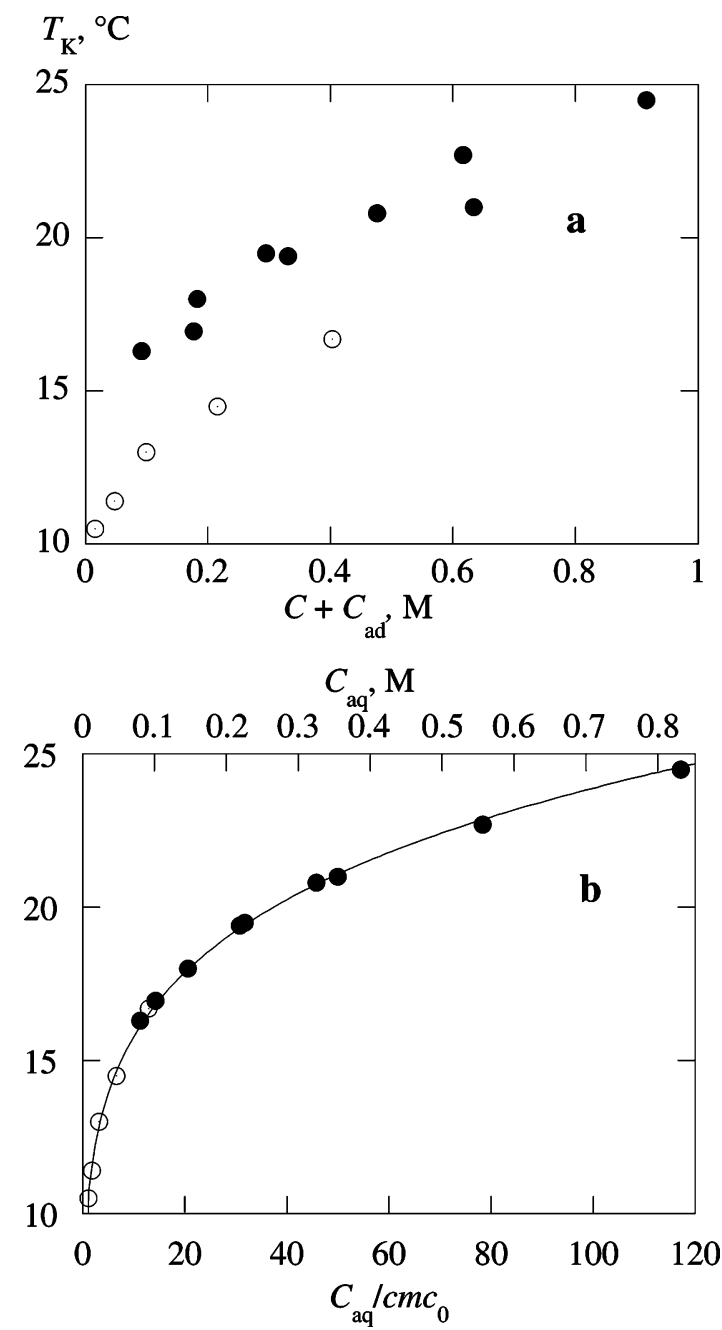

Figure 1. Variation of the Krafft temperature with (a) the total counterion concentration $C+C_{\mathrm{ad}}$ and (b) the counterion concentration in the aqueous phase $C_{\text {aq }}$ with $\alpha=0.20$. Open and closed symbols are for systems without and with added $\mathrm{NH}_{4} \mathrm{Cl}$, respectively.

the fluorescence decay curves to obtain $N$ and the intramicellar quenching rate constant, $k_{\mathrm{Q}}$, can be found in refs 1 and 3 . It suffices to say that in the range between 16 and $35^{\circ} \mathrm{C}$ covered by the experiments the value of the pyrene fluorescence decay time obtained from the fitting of the decay curves to the appropriate equations was found to be the same for systems without and with quencher. This indicated the absence of probe and/or quencher migration in the fluorescence time scale. The values of $N$ and $k_{\mathrm{Q}}$ were determined in the concentration range between 42 and $400 \mathrm{mM}$ and also for selected solutions in the presence of $\mathrm{NH}_{4} \mathrm{Cl}$.

The EPR measurements and data analysis are identical with those described recently. ${ }^{8}$ Computer fits of the EPR spectra yield the line positions, shapes, and heights to high precision. ${ }^{9}$ Mother solutions of AmDS were prepared at concentrations $(C) \sim 400$ $\mathrm{mM}$ containing the spin probe 5DSE. Various combinations of AmDS and $\mathrm{NH}_{4} \mathrm{Cl}$ were prepared from the mother solution by weight. The density of some solutions was measured at 25 and $35^{\circ} \mathrm{C}$ using an Anton Paar oscillating U-tube Density Meter, Model DMA 5000, that was calibrated with water. The values of the density (see Table 1) permitted the conversion of the solution concentration from weight percent to molarity. All EPR spectra in AmDS micelles consisted of three narrow lines typical of nitroxide spectra in the motional narrowing region. Figure 1 in ref 2 gives examples of typical spectra. The hyperfine spacing, 
TABLE 1: Density of Aqueous Solutions of AmDS (g/cm³)

\begin{tabular}{ccc}
\hline$C(\mathrm{M})$ & $25^{\circ} \mathrm{C}$ & $35^{\circ} \mathrm{C}$ \\
\hline 0.04216 & 0.997814 & 0.994720 \\
0.08869 & 0.998542 & 0.995380 \\
0.1990 & 1.000390 & 0.997049
\end{tabular}

TABLE 2: Values (Gauss) of $A_{+}(0)$ and $\left(\delta A_{+} / \delta H\right)$

\begin{tabular}{cccc}
\hline$T\left({ }^{\circ} \mathrm{C}\right)$ & $A_{+}(0)$ & $\left(\delta A_{+} / \delta H\right)$ & $r^{a}$ \\
\hline 10 & $14.231 \pm 0.013$ & $1.454 \pm 0.020$ & 0.998 \\
25 & $14.301 \pm 0.010$ & $1.380 \pm 0.016$ & 0.999 \\
45 & $14.381 \pm 0.007$ & $1.286 \pm 0.011$ & 0.999
\end{tabular}

${ }^{a}$ Coefficient of correlation.

TABLE 3: AmDS: Values of the $\mathrm{cmc}_{0}$ and the Micelle Ionization Degree (Evans' Method)

\begin{tabular}{ccccc}
\hline $\begin{array}{c}T \\
\left({ }^{\circ} \mathrm{C}\right)\end{array}$ & $\begin{array}{c}\mathrm{cmc}_{0} \\
(\mathrm{mM})\end{array}$ & $\alpha$ & $\begin{array}{c}\lambda^{\circ}\left(\mathrm{NH}_{4}{ }^{+}\right) \\
\left(\mathrm{S} \cdot \mathrm{cm}^{2} \cdot \text { equiv }^{-1}\right)^{a}\end{array}$ & $N^{0 b}$ \\
\hline 10 & 7.4 & 0.19 & 53.2 & 77 \\
25 & 7.1 & 0.20 & 73.6 & 70 \\
40 & 7.6 & 0.22 & 96.7 & 61
\end{tabular}

${ }^{a}$ Values used in the calculation of $\alpha$, from ref $12 .{ }^{b}$ See Table 7. Estimated relative error $\pm 5 \%$.

$A_{+}$, was measured for 5DSE as the difference in resonance fields of the center- and low-field lines. This spacing is linearly correlated with the hydrophilicity index at temperature $T\left({ }^{\circ} \mathrm{C}\right)$, $H(T)$, defined by Mukerjee et al. ${ }^{10}$ A calibration of $A_{+}$versus $H\left(25^{\circ} \mathrm{C}\right)$ was given previously. ${ }^{11}$ We present data at temperatures other than $25^{\circ} \mathrm{C}$, so an extension of the calibration must be made to other temperatures. The details of this calibration are given in the Appendix, yielding

$$
A_{+}=A_{+}(0)+\left(\delta A_{+} / \delta H\right) H(T)
$$

Table 2 lists the values of $A_{+}(0)$ and $\left(\delta A_{+} / \delta H\right)$.

\section{Results and Discussion}

Critical Micelle Concentration in the Absence of Salt. The values of the $\mathrm{cmc}_{0}$, the critical micelle concentration in the absence of added salt, at 10,25 , and $40{ }^{\circ} \mathrm{C}$ are listed in Table 3 . They indicate the presence of a rather flat minimum broadly located around $25^{\circ} \mathrm{C}$, a behavior already noted for SDS and TAADS surfactants. ${ }^{1}$

Micelle Ionization Degree from Conductivity Measurements. The plots of the specific conductivity $K$ versus $C$ have been used to obtain the values of $\alpha$ at the investigated temperatures. Evans' $\operatorname{method}^{7}$ requires the values of the equivalent conductivity $\lambda^{\circ}\left(\mathrm{NH}_{4}{ }^{+}\right)$of the ammonium ion and of the micelle aggregation number at the $\mathrm{cmc}, N^{0}$. The values of $\lambda^{\circ}\left(\mathrm{NH}_{4}{ }^{+}\right)$used in the calculations (see Table 3 ) were obtained from the compilation of Robinson and Stokes. ${ }^{12}$ The values of $N^{0}$ listed in Table 3 were obtained from the fitting of eq 5 (see below) to the $N$ versus $C_{\text {aq }}$ data presented. The values of $\alpha$ listed in Table 3 increase very slightly with temperature, as already found for other surfactants. ${ }^{1,13-16}$

Krafft Temperature. Table 4 lists the value of the Krafft temperature, $T_{\mathrm{K}}$, determined for various AmDS solutions in the absence and presence of $\mathrm{NH}_{4} \mathrm{Cl}$ at a concentration $C_{\text {ad }}$. Figure 1a shows a plot of $T_{\mathrm{K}}$ against the total counterion concentration $C+C_{\text {ad. }}$ The results fall on two well-separated curves. As in previous studies ${ }^{17,18}$ the same results have been plotted against the concentration $C_{\mathrm{aq}}$ of free counterions in the aqueous phase which is given by eq $2^{1,2}$

$$
C_{\mathrm{aq}}=\left[\alpha C+(1-\alpha) C_{\text {free }}+C_{\mathrm{ad}}\right] /(1-V C)
$$

TABLE 4: Krafft Temperature of Solutions of AmDS in Water and Water + Ammonium Chloride

\begin{tabular}{lll}
\hline$C(\mathrm{M})$ & $C_{\mathrm{ad}}(\mathrm{M})$ & $T_{\mathrm{K}}\left({ }^{\circ} \mathrm{C}\right)$ \\
\hline 0.0992 & 0 & 13.0 \\
0.0989 & 0.0781 & 16.95 \\
0.2156 & 0 & 14.5 \\
0.2135 & 0.2626 & 20.8 \\
0.09473 & 0.2002 & 19.5 \\
0.1520 & 0.1787 & 19.4 \\
0.09357 & 0.5234 & 22.7 \\
0.1486 & 0.7682 & 24.5 \\
0.40301 & 0 & 16.7 \\
0.3994 & 0.2348 & 21.0 \\
0.0476 & 0 & 11.4 \\
0.0474 & 0.135 & 18.0 \\
0.01582 & 0 & 10.5 \\
0.01577 & 0.07573 & 16.31
\end{tabular}

In eq 2 the factor $1-V C$ ( $V=$ molar volume of the surfactant $)$ corrects the concentration for the volume excluded by the micelles: $C_{\text {free }}$ is the concentration of free (nonmicellar) surfactant given by ${ }^{19,20}$

$$
\log C_{\text {free }}=(2-\alpha) \log \mathrm{cmc}_{0}-(1-\alpha) C_{\mathrm{aq}}
$$

Values of $\alpha$ may be derived from the hypothesis that $N$ is a function of $C_{\mathrm{aq}}$ only as is discussed in detail in ref 5. Briefly, the method relies on measurements of any physical quantity that varies monotonically as a function of $N$. Matching two samples with the same value of $N$ yields a value of $\alpha$ from eq $2 .^{5}$ Further, by assuming $\alpha$ to be constant, common curves of the physical constant versus $C_{\mathrm{aq}}$ are found by adjusting the value of $\alpha$ in eq 2.5

The values of $C_{\text {aq }}$ and $C_{\text {free }}$ have been obtained from eqs 2 and 3, using a constant value of $\alpha=0.20$, the value that gave the best common curve in Figure 1b. Using a linearly varying value of $\alpha$ from 0.19 to 0.20 in the range of temperature between 10 and $25{ }^{\circ} \mathrm{C}$ (see Table 1; the very small, within the experimental error, increase of $\alpha$ as $T$ is increased from 10 to $25^{\circ} \mathrm{C}$ supports the use of a constant value of $\alpha$ for the fitting of the Krafft temperature data in Figure 1) gives a plot imperceptibly different from that shown.

The solid line in Figure $1 \mathrm{~b}$ is the least-squares fit to the following

$$
T_{\mathrm{K}}=T_{\mathrm{K}}^{0}\left(C_{\mathrm{aq}} / \mathrm{cmc}_{0}\right)^{\gamma_{\mathrm{K}}}
$$

where $\gamma_{\mathrm{K}}=0.180 \pm 0.002$; and $T_{\mathrm{K}}{ }^{0}=10.42 \pm 0.07{ }^{\circ} \mathrm{C}$ is the Krafft temperature at the $\mathrm{cmc}_{0}$ that is the Krafft point of AmDS. Thus the Krafft temperature varies with $C_{\mathrm{aq}}$ with the same functional form as the micelle aggregation number.

An independent determination of the Krafft point comes from the partial phase diagram of AmDS shown in Figure 2. In this figure the $\mathrm{cmc}_{0}$ and the solubility $S$ of AmDS in water are plotted as a function of $T$. The values of the solubility are those of the AmDS concentration in solutions for which the Krafft temperature has been determined in the absence of salt (see Table 4). The extrapolation of the solubility plot intercepts the cmc plot at a temperature slightly above $10^{\circ} \mathrm{C}$, which represents the Krafft point of AmDS, in excellent agreement with the value resulting from the fitting of the $T_{\mathrm{K}}$ data to eq 4 .

Aggregation Number of AmDS Micelles in Aqueous Solution. The values of $N$ at different $T, C$, and $C_{\text {ad }}$ are listed in Table 5. These values were calculated, as detailed in ref 1 , using for the concentration of micellized surfactant the quantity $C-C_{\text {free, }}$, where the concentration of free surfactant was calculated using eqs 2 and 3 . 
$C(m M)$

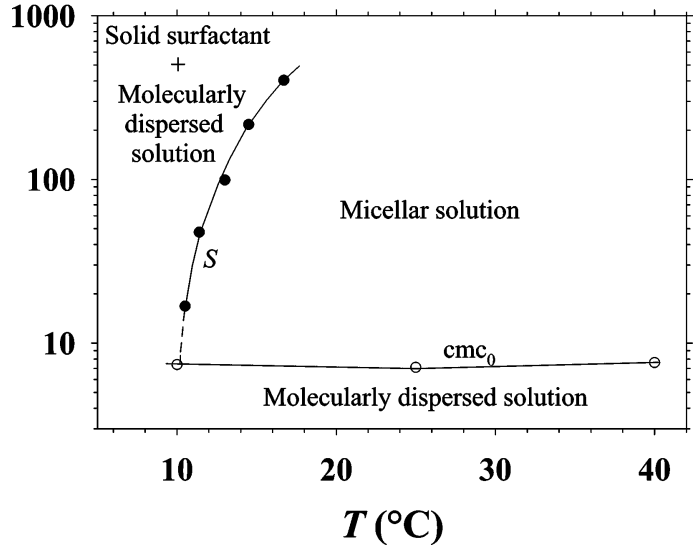

Figure 2. Partial phase diagram of the AmDS/water mixture $(S=$ solubility of AmDS in water).

TABLE 5: Aggregation Number of AmDS Micelles in Water and Aqueous Ammonium Chloride Solutions

\begin{tabular}{|c|c|c|c|c|}
\hline$C(\mathrm{mM})$ & $C_{\text {ad }}(\mathrm{mM})$ & $T\left({ }^{\circ} \mathrm{C}\right)$ & $N^{a}$ & $10^{-7} k_{\mathrm{Q}}\left(\mathrm{s}^{-1}\right)$ \\
\hline \multirow[t]{3}{*}{42.2} & 0 & 16 & 89 & 2.42 \\
\hline & & 25 & 81.5 & 3.65 \\
\hline & & 35 & 70 & 5.02 \\
\hline \multirow[t]{3}{*}{88.8} & 0 & 16 & 97.6 & 2.24 \\
\hline & & 25 & 89.6 & 3.30 \\
\hline & & 35 & 79.1 & 4.70 \\
\hline \multirow{3}{*}{49.06} & 8.75 & 16 & 97.4 & 2.28 \\
\hline & & 25 & 87.4 & 3.28 \\
\hline & & 35 & 77.3 & 4.62 \\
\hline \multirow[t]{3}{*}{200} & 0 & 16 & 113 & 1.97 \\
\hline & & 25 & 103 & 2.91 \\
\hline & & 35 & 87.7 & 3.95 \\
\hline \multirow{3}{*}{100.1} & 22.25 & 16 & 117.7 & 2.01 \\
\hline & & 25 & 104 & 2.92 \\
\hline & & 35 & 90.8 & 4.05 \\
\hline \multirow[t]{3}{*}{49.91} & 33.8 & 16 & 117.9 & 1.96 \\
\hline & & 25 & 103.6 & 2.92 \\
\hline & & 35 & 92.2 & 4.12 \\
\hline \multirow{3}{*}{400.1} & 0 & 16 & 137 & 1.82 \\
\hline & & 25 & 127.2 & 2.63 \\
\hline & & 35 & 110.1 & 3.70 \\
\hline \multirow{3}{*}{100.1} & 71.8 & 16 & 135.5 & 1.77 \\
\hline & & 25 & 122 & 2.59 \\
\hline & & 35 & 108 & 3.86 \\
\hline
\end{tabular}

${ }^{a}$ See Table 7. Estimated relative error $\pm 5 \%$.

Figure 3a shows that $N$ increases with $C+C_{\text {ad. }}$ The $N$ vs $C$ plots in water $\left(C_{\mathrm{ad}}=0\right)$ at 16,25 , and $35^{\circ} \mathrm{C}$ run nearly parallel. A comparison with the results reported for SDS and CsDS micelles ${ }^{1}$ showed that in the absence of $\mathrm{NH}_{4} \mathrm{Cl}$, for given values of $C$ and $T$, the values of the aggregation number of AmDS micelles are larger than those for SDS micelles and close to those for CsDS micelles. The cmc values of AmDS and CsDS are also close. Thus the observation that for a series of homologous surfactants under given experimental conditions $N$ is larger as the $\mathrm{cmc}_{0}$ is smaller holds for AmDS. Recall that such is not the case with TAADS surfactants which all have smaller $\mathrm{cmc}_{0}$ than SDS but are characterized by micelle aggregation numbers that are lower than those for SDS at least at low concentration and temperature. ${ }^{1}$

Figure $3 \mathrm{a}$ shows that at each temperature the results in the absence of salt (open symbols) define a curve that is clearly different from that for the results in the presence of salt (closed symbols). The same results are represented in Figure $3 \mathrm{~b}$ against $C_{\text {aq }}$ (upper abscissa scale). Values of $\alpha=0.19,0.20$, and 0.21 at 16,25 , and $35^{\circ} \mathrm{C}$, respectively, interpolated from conductivity results were used to compute $C_{\mathrm{aq}}$. The fact that results from the samples with and without added $\mathrm{NH}_{4} \mathrm{Cl}$ form a satisfactory
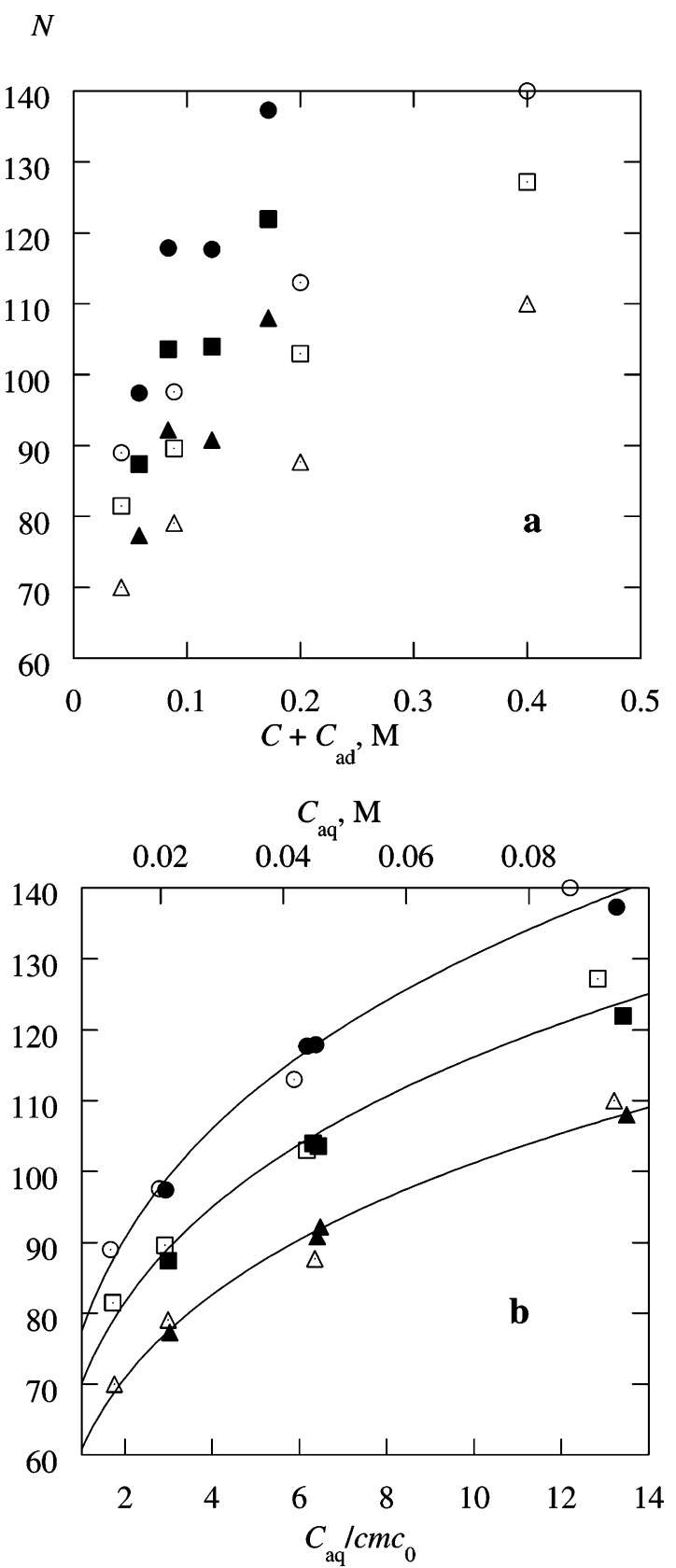

Figure 3. Variation of the aggregation number of AmDS micelles at $16(\bullet, \bigcirc), 25(\square, \square)$, and $35^{\circ} \mathrm{C}(\mathbf{\Delta}, \Delta)$ with (a) the total counterion concentration $C+C_{\text {ad }}$ and (b) with the counterion concentration in the aqueous phase $C_{\mathrm{aq}}$ with $\alpha=0.20$. Open and closed symbols are for systems without and with added $\mathrm{NH}_{4} \mathrm{Cl}$, respectively.

common curve as a function of $C_{\text {aq }}$ demonstrates that $N$ does indeed conform to the hypothesis that the aggregation number is a function of $C_{\mathrm{aq}}$ only, namely $N=N\left(C_{\mathrm{aq}}\right)$, at a constant temperature. Note that plots of $N$ versus $C_{\text {aq }}$ in which both the salt and surfactant concentration were varied are few: Figures 3 and 5 of ref 2, Figure 5 of ref 16 and Figure 5 of ref 21.

Although the statistics are limited and the uncertainties rather large, best values of $\alpha$ may be derived from searching for common curves of the data in Figure $3 \mathrm{a}$. These are given in Table 6 and are seen to give rather good agreement with the conductivity values. The solid lines are the best fits to the power law

$$
N=N^{0}\left(C_{\mathrm{aq}} / \mathrm{cmc}_{0}\right)^{\gamma}
$$

yielding the parameters listed in Table 7. The exponent is 

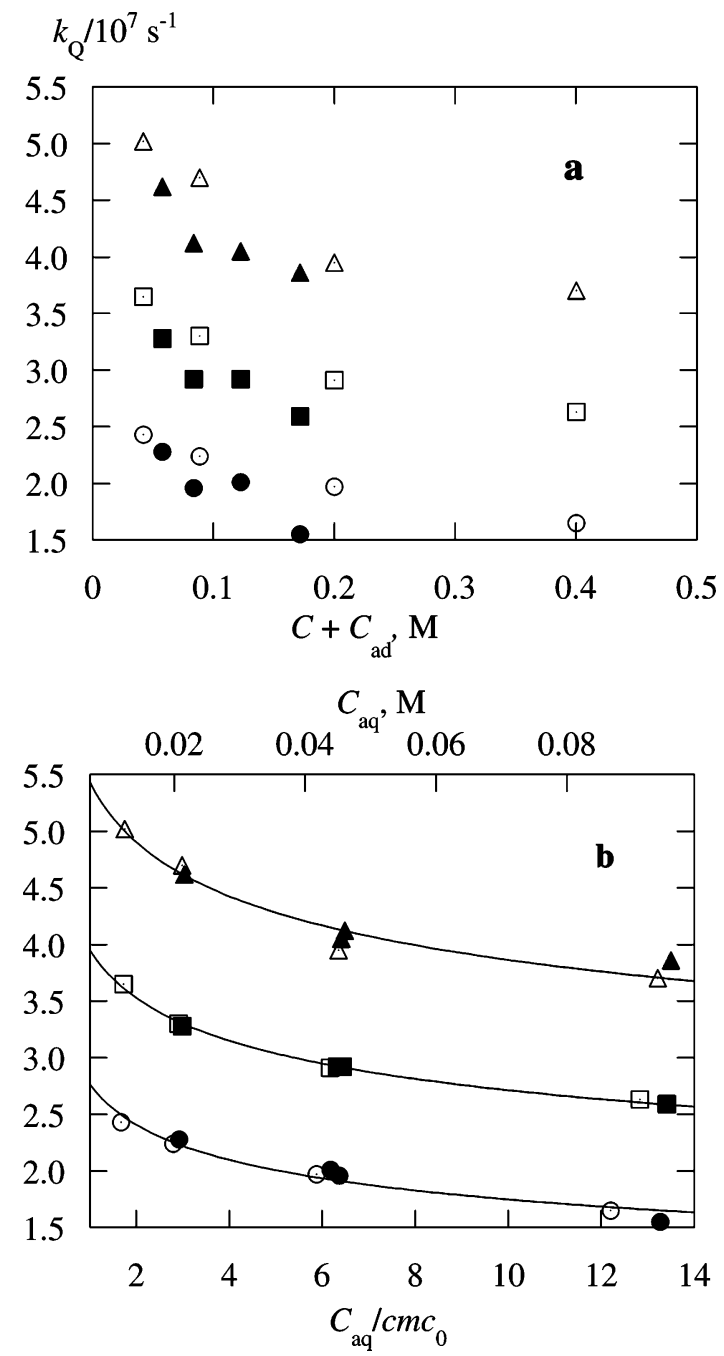

Figure 4. Variation of the quenching rate constant in AmDS micelles at $16(\bullet, \bigcirc), 25(\boldsymbol{\square}, \square)$, and $35^{\circ} \mathrm{C}(\boldsymbol{\Delta}, \Delta)$ with (a) the total counterion concentration $C+C_{\text {ad }}$ and (b) with the counterion concentration in the aqueous phase $C_{\text {aq }}$ with $\alpha=0.20$. Open and closed symbols are for systems without and with added $\mathrm{NH}_{4} \mathrm{Cl}$, respectively.

constant within experimental error: $\gamma=0.222 \pm 0.004$. The temperature dependence of $N^{0}$ is given by eq 6

$$
N^{0}=(91.6 \pm 0.9)-(0.875 \pm 0.034) T
$$

with $T$ in ${ }^{\circ} \mathrm{C}$. This value of the temperature coefficient of the aggregation number may be compared with the results of Malliaris et al. ${ }^{22}$ for SDS, who found that $N$ varies approximately linearly with $T$ with a coefficient of -0.84 , very close to the present result. In Figure $3 b$ the lower abscissa scale uses the reduced concentration $C_{\mathrm{aq}} / \mathrm{cmc}_{0}$ to show the range of validity of the scaling law eq 5 .

Micelles of AmDS, therefore, fit the growth law, eq 5, that has been found to describe micelle growth with increasing surfactant and/or salt concentrations in the slow-growth region for dodecyl sulfate micelles with counterions $\mathrm{Na}^{+}, 23 \mathrm{Li}^{+}, 24$ TMADS, TEADS, and TPADS, ${ }^{2}$ dodecyltrimethylammonium bromide, and chloride; ${ }^{16}$ the sodium alkyl sulfates with chain lengths $8-14,25,26$ and cetyltrimethylammonium chloride and acetate. ${ }^{27}$ The only surfactant that we have studied that did not conform to eq 1 was TBADS, a very unusual surfactant indeed. ${ }^{3}$

Intramicellar Quenching Rate Constants. The fittings of the decay curves in the presence of the $\mathrm{DPyCl}$ quencher yielded also the values of the intramicellar quenching rate constant $k_{\mathrm{Q}}$
$H\left(25^{\circ} \mathrm{C}\right)$

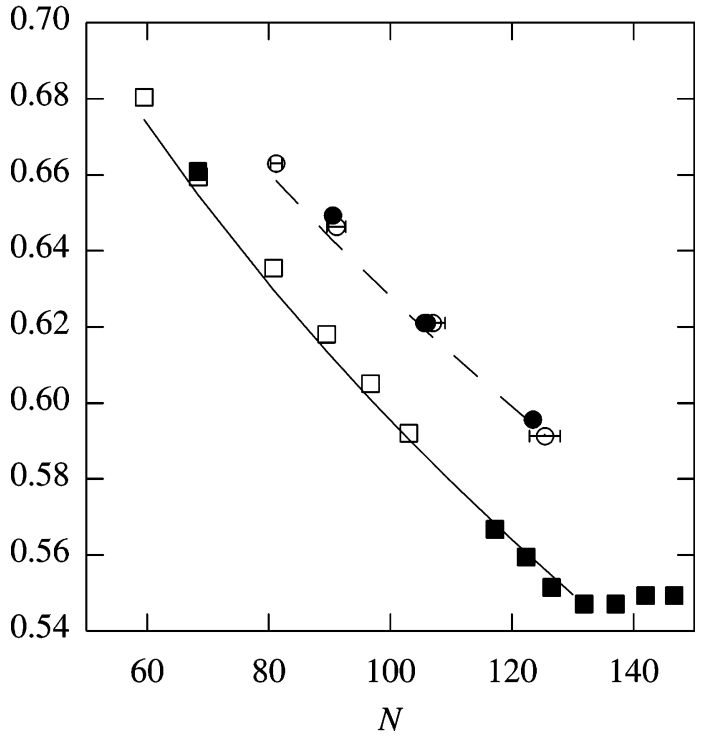

Figure 5. Variation of the polarity scale $H\left(25^{\circ} \mathrm{C}\right)$ with aggregation number of micelles of $\operatorname{AmDS}(\bullet, O)$ and $\operatorname{SDS}(\boldsymbol{\square}, \square)$ from ref 11 . Open and closed symbols are for systems without added $\mathrm{NH}_{4} \mathrm{Cl}$ or $\mathrm{NaCl}$, respectively. The solid line is a plot of eq 10 with the parameters given in the text and the dashed line is a plot of eq 12 with no further adjustable parameters. The abscissa is computed from eq 5 with $\alpha=$ $0.27, \gamma=0.25$, and $N^{0}=49$ for $\operatorname{SDS}^{23}$ and with $\alpha=0.23, \gamma=0.22$, and $N^{0}=70$ for AmDS. The horizontal error bars indicate the uncertainty due to a $\pm 10 \%$ uncertainty in the value of $\alpha$.

TABLE 6: Values of $\alpha$ from the Aggregation Number-Based Definition, Eq 5

\begin{tabular}{lcclc}
\hline \multicolumn{1}{c}{ method } & quantity $^{a}$ & \multicolumn{1}{c}{$16^{\circ} \mathrm{C}$} & \multicolumn{1}{c}{$25^{\circ} \mathrm{C}$} & \multicolumn{1}{c}{$35^{\circ} \mathrm{C}$} \\
\hline EPR & $A_{+}$ & $0.22 \pm 0.02$ & $0.23 \pm 0.02$ & $0.25 \pm 0.02$ \\
EPR & $\eta_{\text {micro }}$ & $0.20 \pm 0.02$ & $0.23 \pm 0.02$ & $0.23 \pm 0.02$ \\
TRFQ & $N$ & $0.20 \pm 0.02$ & $0.25 \pm 0.02$ & $0.21 \pm 0.02$ \\
TRFQ & $k_{\mathrm{Q}}$ & $0.19 \pm 0.02$ & $0.20 \pm 0.02$ & $0.27 \pm 0.04$ \\
clearing temp & $\mathrm{T}_{\mathrm{K}}$ & $0.20 \pm 0.02^{c}$ & $0.20 \pm 0.02^{c}$ & \\
conductivity $^{b}$ & & 0.19 & 0.20 & 0.21
\end{tabular}

${ }^{a}$ The quantity used to form a common curve versus $C_{\text {aq }}{ }^{b}$ For comparison. Interpolated from Table $1 .{ }^{c}$ Average over $T_{\mathrm{K}}=11$ to 25 ${ }^{\circ} \mathrm{C}$.

TABLE 7: Aggregation Numbers of AmDS Micelles and Parameters from Eq 5

\begin{tabular}{cccc}
\hline$T\left({ }^{\circ} \mathrm{C}\right)$ & $N^{0}$ & $\gamma$ & $\alpha^{a}$ \\
\hline 35 & $60.8 \pm 1.5$ & $0.221 \pm 0.014$ & 0.19 \\
25 & $70.1 \pm 1.9$ & $0.219 \pm 0.014$ & 0.20 \\
16 & $77.4 \pm 1.6$ & $0.227 \pm 0.010$ & 0.21
\end{tabular}
5 .

${ }^{a}$ Value of $\alpha$ assumed to fit values of $N$ as a function of $C_{\text {aq }}$ from eq

that are listed in Table 5. At each temperature the value of the product $N k_{\mathrm{Q}}$ was found to be constant (independent of the value of $N$ ) up to a concentration $C=200 \mathrm{mM}$. This behavior suggests that the AmDS micelles are close to spherical in these concentration and temperature ranges. ${ }^{28}$ The value of the product $N k_{\mathrm{Q}}$ became larger as $C$ was increased to $400 \mathrm{mM}$. This increase probably indicates that the micelles can no longer be considered as spherical at this concentration (the values of $N$ are then equal to or larger than 110).

Values of the quenching rate constant of pyrene by $\mathrm{DPyCl}$ as a function of $C+C_{\text {ad }}$ are plotted in Figure $4 \mathrm{a}$ at 16, 25, and $35^{\circ} \mathrm{C}$ and again versus $C_{\mathrm{aq}}$ in Figure $4 \mathrm{~b}$. Values of $\alpha=0.19$, 0.20 , and 0.21 , interpolated from conductivity results, were used in computing $C_{\mathrm{aq}}$. Figure $4 \mathrm{~b}$ demonstrates that $k_{\mathrm{Q}}$, being another property that varies monotonically with $N$, forms suitable 
common curves versus $C_{\text {aq }}$. Searching for the best common curves yields the values of $\alpha$ deduced from $k_{\mathrm{Q}}$ in Table 6 . While $k_{\mathrm{Q}}$ may not be the method of choice to determine $\alpha$, especially with poor statistics, it is clear that it supports the aggregation number-based definition of $\alpha$.

EPR Determination of the AmDS Micelle Hydration and Ionization Degree. The values of the hyperfine spacing, $A_{+}$, were measured for 5DSE. The micelle hydrophilicity index $H(T)$ at temperature $T$ was then obtained using the calibration curves presented in the Table 2.

Figure 5 shows the values of $H\left(25^{\circ} \mathrm{C}\right)$ for AmDS micelles together with values for SDS micelles taken from Figure 5 of ref 11 . These latter values are plotted here with two slight differences from the original: first, the abscissa is computed by taking into account the excluded volume factor $1 /(1-V C)$ in eq 2, which was neglected previously, ${ }^{11}$ and second, the calibration eq 1 is used rather than the original calibration. These differences are barely perceptible on the scale of Figure 5. AmDS micelles show decreasing values of $H(T)$ as $N$ increases. Similar plots at 16 and $35{ }^{\circ} \mathrm{C}$ (not shown) show that the hydration decreases as the temperature increases for a given value of $N$. Compare with the analogous behavior with temperature found for TMADS micelles in Figure 1 of ref 4.

To compare the experimental results of Figure 5 to theory we employ the same simple model to predict the hydration of AmDS micelles that has been successful in interpreting data in other micelles, for instance, SDS ${ }^{11}$ and dodecyltrimethlammonium chloride and bromide. ${ }^{16}$ An important test of the model involved inserting bulky sugar-group headgroups into SDS. ${ }^{29}$ Full details may be found in refs 11, 16, and 29 and references therein, especially discussion of the assumptions concerning the location of the spin probe. Here our purpose is to explore the effect of substituting the ion $\mathrm{Na}^{+}$by $\mathrm{NH}_{4}{ }^{+}$on the hydration of the dodecyl sulfate micelle; thus we briefly summarize. The micelle is assumed to be a sphere of radius $R_{\mathrm{m}}$ composed of a hydrophobic core of radius $R_{\mathrm{c}}$ and a polar shell (the Stern layer) of thickness $R_{\mathrm{m}}-R_{\mathrm{c}}$. The core radius is evaluated from

$$
N V_{\text {tail }}=\frac{4 \pi}{3} R_{\mathrm{c}}^{3}
$$

where the volume of one alkyl chain (tail) embedded in the micelle core is given by

$$
V_{\text {tail }}=27.4+26.9\left(m-m_{\text {wet }}\right)
$$

In eq $8, m=12$ (number of carbon atoms in the dodecyl sulfate alkyl chain) and $m_{\text {wet }}$ is the number of methylene groups that are located in the polar shell in contact with water. The volumes of the polar shell and of the micelle are given by

$$
V_{\text {shell }}=\frac{4 \pi}{3}\left(R_{\mathrm{m}}^{3}-R_{\mathrm{c}}^{3}\right) \quad \text { and } \quad V_{\text {micelle }}=\frac{4 \pi}{3} R_{\mathrm{m}}^{3}
$$

Recall that the nonempirical polarity scale $H\left(25^{\circ} \mathrm{C}\right)$, introduced by Mukerjee et al., ${ }^{10}$ was defined to be the ratio of the molar concentration of $\mathrm{OH}$ dipoles in a solvent or solvent mixture to that in water. In many micelles, such as SDS, where there are no hydrogen bonding molecules other than water, $H\left(25^{\circ} \mathrm{C}\right)$, is equal to the volume fraction occupied by water. Thus for those cases ${ }^{16}$

$$
H\left(25^{\circ} \mathrm{C}\right)=\frac{V_{\text {shell }}-N V_{\text {dry }}}{V_{\text {shell }}}
$$

where $V_{\text {dry }}$ is the volume per surfactant molecule that is inaccessible to water, which may be computed from

$$
V_{\mathrm{dry}}=\left[V_{\mathrm{hg}}+(1-\alpha) V_{\mathrm{ci}}+m_{\mathrm{wet}} \mathrm{V}_{\mathrm{CH}_{2}}\right]
$$

where $V_{\mathrm{hg}}, V_{\mathrm{ci}}$, and $\mathrm{V}_{\mathrm{CH}_{2}}$ are the volume of the headgroup, counterion, and methylene group, respectively. In the case where the counterion hydrogen bonds to the nitroxide, eq 10 must be modified by adding the hydrogen bonds due to $N(1-\alpha)$ counterions which normalized to the number of water dipoles in the same volume, yielding an additional term in eq 10 equal to $N(1-\alpha)\left(V_{\text {water }} / V_{\text {shell }}\right)$, where $V_{\text {water }}$ is the volume of one water molecule. Therefore eq 10 becomes the following for hydrogen bonding counterions:

$$
H\left(25^{\circ} \mathrm{C}\right)=\frac{V_{\text {shell }}-N V_{\text {dry }}+N(1-\alpha) V_{\text {water }}}{V_{\text {shell }}}
$$

Equation 12 assumes that the strength of the hydrogen bond is the same for a water molecule and for an $\mathrm{NH}_{4}{ }^{+}$ion. One could insert a factor that would take into account a possible difference in the hydrogen bonding strength of the two moieties; however, this would introduce an additional parameter and we find that it is not needed to satisfactorily account for the data.

To interpret the AmDS data we require that eq 10 fits SDS data and that eq 12 predicts the values for AmDS without any further adjustable parameters.

We first discuss the solid line through the SDS data in Figure 5. This line is computed from eq 10 neglecting $V_{\mathrm{ci}}$ and using a polar shell thickness $R_{\mathrm{m}}-R_{\mathrm{c}}=5 \AA$ just as before. ${ }^{11}$ As discussed previously, ${ }^{11}$ the theoretical curve has only one adjustable parameter, which we took to be $V_{\text {dry }}$, having assumed the simplest model by adopting a value of $m_{\text {wet }}=0$. That resulted in $V_{\text {dry }}=127 \AA^{3}$. Applying the same model here yields $V_{\text {dry }}=132 \AA^{3}$, a $4 \%$ increase due to the two adjustments mentioned above. We reiterate ${ }^{11,16,29}$ that other combinations of the shell thickness, $V_{\text {dry }}$ and $m_{\text {wet }}$, produce essentially the same curve. Based solely on EPR measurements, these details are indiscernible because we only measure the volume fraction occupied by water. The model is persuasive because the slope of the solid line is fixed and agrees with experiment; no further adjustable parameters are involved.

We now turn to the data from AmDS in Figure 5. The dashed line is computed from eq 12 using the same fit parameters as those for the solid line with $V_{\mathrm{ci}}=V_{\mathrm{NH}_{4}}{ }^{+}=17.5 \AA^{3}$. Note that the larger size of the $\mathrm{NH}_{4}{ }^{+}$ion lowers the value of $H\left(25^{\circ} \mathrm{C}\right)$ with respect to SDS, but the hydrogen bonding of the $\mathrm{NH}_{4}{ }^{+}$ ion raises it, the latter dominating in this case. The excellent fit not only in magnitude but also in slope lends further support to the simple hydration model in that no adjustable parameters are involved.

The data for AmDS in Figure 5 show that a good common curve is obtained for both zero-salt and added salt samples. The abscissa of Figure 5 is computed using $\alpha=0.20$, the value that minimizes the difference between the experimental points and a linear approximation to the variation of $H\left(25^{\circ} \mathrm{C}\right)$ with $N$. The horizontal error bars show the uncertainty in $N$ produced by an uncertainty of $\pm 10 \%$ in $\alpha$. Searching for the common curve at 16 and $35^{\circ} \mathrm{C}$ yields the values of $\alpha$ given in the first row of Table 6 .

Microviscosity of the Polar Shell. Values of the rotational correlation time of the doxyl moiety of 5DSE were obtained from the line height ratios $^{30}$ and microviscosities, $\eta_{\text {micro }}$, were computed as recently detailed. ${ }^{16}$ Figure 6 shows the variation of the microviscosity at 16,25 , and $35^{\circ} \mathrm{C}$, as a function of $N$ for AmDS together with similar results for SDS at $25^{\circ} \mathrm{C}$, 


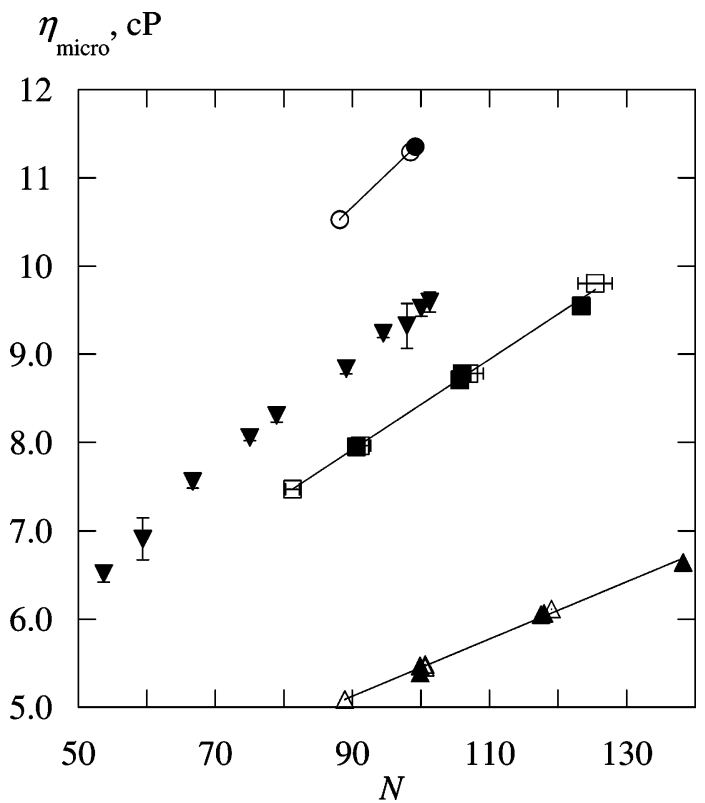

Figure 6. Variation of the microviscosity with aggregation number of AmDS micelles at $16(\bullet, 0), 25(\boldsymbol{\square}, \square)$, and $35^{\circ} \mathrm{C}(\boldsymbol{\Lambda}, \Delta)$ and SDS micelles at $25^{\circ} \mathrm{C}(\boldsymbol{\nabla})$. Open and closed symbols are for systems without and with added $\mathrm{NH}_{4} \mathrm{Cl}$, respectively. For SDS the abscissa is the same as in Figure 5 and for AmDS it is computed from eq 5 using the parameters in row 2 of Table 6 for $\alpha$ and Table 7 for $\gamma$ and $N^{0}$. The horizontal error bars indicate the uncertainty due to a $\pm 10 \%$ uncertainty in the value of $\alpha$.

derived from spectra taken from the literature. ${ }^{5}$ The variation of $\eta_{\text {micro }}$ with $N$ is modest in all cases and similar to each other. For AmDS, the abscissa is computed using values of $\alpha$ that produce the best common curves, Table 6, and for SDS, $\alpha=$ $0.27,{ }^{23}$ the horizontal error bars on the $25^{\circ} \mathrm{C}$ data, corresponding to a variation of $\alpha$ by $\pm 10 \%$. Values of $\eta_{\text {micro }}$ taken from Figure 6 at a common value of $N=90$ when plotted as the $\ln \left(\eta_{\text {micro }}\right)$ vs $1 / T$ where $T$ is here the absolute temperature form a straight line (not shown) with a coefficient of correlation $(r)$ of 0.9998 and yield an activation energy for the microviscosity of 21.5 $\mathrm{kJ} / \mathrm{mol}$. This value is smaller than that found for the TAADS surfactant micelles (around $29 \mathrm{~kJ} / \mathrm{mol}$ ). ${ }^{4}$ The activation energy of the microvicosity of AmDS micelles has also been determined from the slope of the $N k_{\mathrm{Q}}$ versus $1 / T$ plots (not shown) using the values listed in Table 5 . This yielded values ranging between 19 and $21 \mathrm{~kJ} / \mathrm{mol}$. This value compares well with the EPR value. Also it is close to the values obtained from the $N k_{\mathrm{Q}}$ versus $1 / T$ plot for SDS, CsDS, and TAADS micelles. ${ }^{1}$

\section{Conclusions}

This study has provided several new pieces of information on the properties of the ammonium dodecyl sulfate surfactant (Krafft temperature, $\mathrm{cmc}$ ) and the properties of its micelles (micelle aggregation number, microviscosity, and hydration and intramicellar quenching rate constant). The ionization degree $\alpha$ of AmDS micelles has been determined from electrical conductivity data using Evans' method. It has also been obtained from the variation of the Krafft temperature, micelle aggregation number, intramicellar quenching rate constant, micelle microviscosity, and apparent micelle hydration, on the assumption that the micelle aggregation number depends only on the concentration of free counterions (here $\mathrm{NH}_{4}{ }^{+}$), whether they come from the micelle ionization or from added $\mathrm{NH}_{4} \mathrm{Cl}$. The various methods yielded values of $\alpha$ that are in agreement, within the experimental uncertainty. In this respect AmDS
$A_{+}(T), \mathrm{G}$

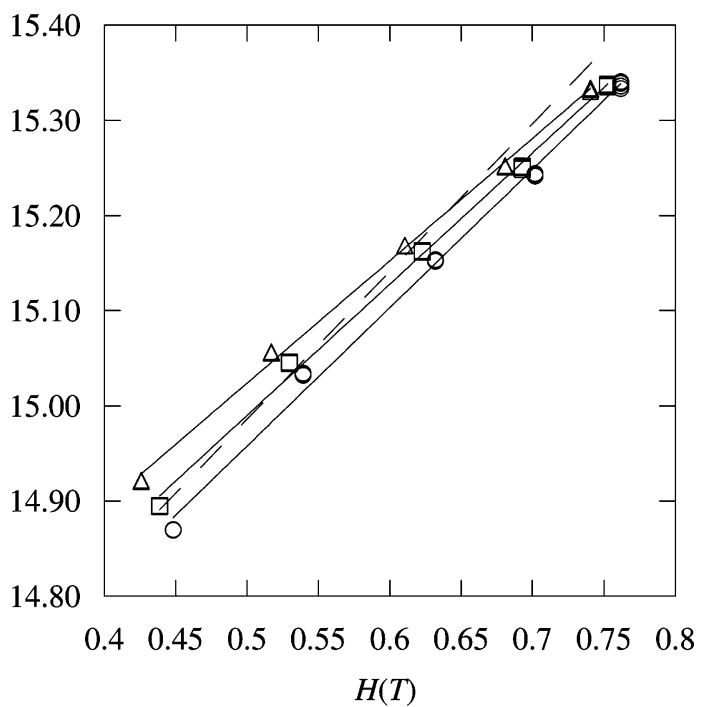

Figure 7. Variation of the hyperfine spacing of 5DSE with polarity indices $H(T)$ at $10(\bigcirc), 25(\bullet)$, and $45{ }^{\circ} \mathrm{C}(\triangle)$. The solid lines are linear least-squares fits to eq 1 yielding the data in Table 2 . The dashed line is a previously published calibration at $25^{\circ} \mathrm{C} . .^{11}$

behaves rather differently from the tetraalkylammonium dodecyl sulfates for which Evans' method yielded values of $\alpha$ smaller than the aggregation number-based methods. Thus we have extended to anionic surfactants with a counterion having a size larger than $\mathrm{Cs}^{+}$the range of surfactants for which the aggregation number-based method for obtaining $\alpha$ applies. Nevertheless, this study did not permit us to find out why the TAADS surfactants do not conform to the scheme followed by all the other anionic surfactants investigated thus far. Is it the size of the counterion and/or its hydrophobicity that matter? A future study will attempt to address this problem by synthesizing and investigating a dodecyl sulfate surfactant with a very large hydrophilic counterion.

\section{Appendix}

Calibration of $\boldsymbol{A}_{+}$Versus the Hydrophilicity Index for 5DSE. The EPR of 5DSE was studied in methanol/water mixtures at 10,25 , and $45^{\circ} \mathrm{C}$. The preparation of the aqueous alcohol mixtures and the measurements have been described in detail. ${ }^{11}$ The hydrophilicity index, $H(T)$, for methanol/water mixtures is given as follows: ${ }^{4}$

$$
H(x, T)=(1.003-0.441 x) \rho(x, T)
$$

where $\rho(x, T)$ is the density of the solution and $x$ is the weight fraction of $\mathrm{MeOH}$. Employing experimental values ${ }^{31}$ of $\rho(x, T)$ for methanol/water mixtures, $H(x, T)$ was computed for each of the solvent mixtures from eq A1.

The temperature was measured to within $\pm 0.2{ }^{\circ} \mathrm{C}$ with a thermocouple placed directly into the cavity.

Figure 7 shows values of $A_{+}(T)$ versus $H(T)$ at the three temperatures. The solid lines are linear least-squares fits yielding the parameters in Table 2 . A calibration of $A_{+}\left(25^{\circ} \mathrm{C}\right)$ vs $H\left(25^{\circ} \mathrm{C}\right)$ was previously published, ${ }^{11}$ which is shown by the dashed line in Figure 7. This new calibration is in good agreement with the previous one at low values of $H\left(25^{\circ} \mathrm{C}\right)$ to about $H\left(25^{\circ} \mathrm{C}\right)=$ 
0.62 , but deviates to smaller values above this. Previous work using the old calibration is only slightly altered, because most values of $H\left(25^{\circ} \mathrm{C}\right)$ found in micelles have been less than 0.7 .

Acknowledgment. We gratefully acknowledge support from NIH/MBRS S06 GM48680-09 and the CNRS.

\section{References and Notes} 13432

(1) Benrraou, M.; Bales, B. L.; Zana, R. J. Phys. Chem. B 2003, 107,

(2) Bales, B. L.; Tiguida, K.; Zana, R. J. Phys. Chem. B 2004, 108, 14948.

(3) Zana, R.; Benrraou, M.; Bales, B. L. J. Phys. Chem. B 2004, 108 , 18195

(4) Bales, B. L.; Benrraou, M.; Tiguida, K.; Zana, R. J. Phys. Chem. B 2005, 109, 7987.

(5) Bales, B. L. J. Phys. Chem. B 2001, 105, 6798.

(6) Bales, B. L. An Aggregation Number-Based Definition of the Ionization of a Micelle. Demonstration with TRFQ, SANS, and EPR. In Magnetic Resonance in Colloid and Interface Science; Fraissard, J., Lapina, O. ,Eds.; Kluwer Academic Publ.: Dordrecht, The Netherlands, 2002; Vol $76, \mathrm{p} 277$

(7) Evans, H. C. J. Chem. Soc. 1956, 579

(8) Bales, B. L.; Ranaganathan, R.; Griffiths, P. C. J. Phys. Chem. B 2001, 105, 7465 .

(9) Halpern, H. J.; Peric, M.; Yu, C.; Bales, B. L. J. Magn. Reson. 1993, 103, 13.

(10) Mukerjee, P.; Ramachandran, C.; Pyter, R. A. J. Phys. Chem. 1982 $86,3189$.

(11) Bales, B. L.; Messina, L.; Vidal, A.; Peric, M.; Nascimento, O. R. J. Phys. Chem. B 1998, 102, 10347.

(12) Robinson, R. A.; Stokes, R. H. Electrolyte Solutions, 2nd ed. (revised); Butterworth: London, UK, 1959; p 465.
(13) Zana, R. J. Colloid Interface Sci. 1980, 78, 330.

(14) Barry, B. W.; Wilson, R. Colloid Polym. Sci. 1978, 256, 251.

(15) Shanks, P. C.; Franses, E. I. J. Phys. Chem. 1992, 96, 1794.

(16) Bales, B. L.; Zana, R. J. Phys. Chem. B 2002, 106, 1926.

(17) Bales, B. L.; Benrraou, M.; Zana, R. J. Phys. Chem. B 2002, 106 , 9033

(18) Vautier-Giongio, C.; Bales, B. L. J. Phys. Chem. B 2003, 107, 5398.

(19) Sasaki, T.; Hattori, M.; Sasaki, J.; Nukina, K. Bull. Chem. Soc. Jpn. 1975, 48, 1397.

(20) Hall, D. G. J. Chem. Soc., Faraday Trans. 1 1981, 77, 1121

(21) Griffiths, P. C.; Paul, A.; Hennan, R. K.; Penfold, J.; Ranganathan, R.; Bales B. L. J. Phys. Chem. B 2004, 108, 3810.

(22) Malliaris, A.; Le Moigne, J.; Sturm, J.; Zana, R. J. Phys. Chem 1985, 89, 2709 .

(23) Quina, F. H.; Nassar, P. M.; Bonilha, J. B. S.; Bales, B. L. J. Phys. Chem. 1995, 99, 17028.

(24) Bales, B. L.; Shahin, A.; Lindblad, C.; Almgren, M. J. Phys. Chem. B 2000, 104, 256 .

(25) Ranganathan, R.; Peric, M.; Bales, B. L. J. Phys. Chem. B 1998, 102,8436 .

(26) Ranganathan, R.; Tran, L.; Bales, B. L. J. Phys. Chem. B 2000 , 104, 2260.

(27) Ranganathan, R.; Okano, L. T.; Yihwa, C.; Quina, F. H. J. Colloid Interface Sci. 1999, 214, 238.

(28) Van der Auweraer, M.; De Schryver, F. C. J. Phys. Chem. 1972, 76, 3020 .

(29) Bales, B. L.; Howe, A. M.; Pitt, A. R.; Roe, J. A.; Griffiths, P. C. J. Phys. Chem. B 2000, 104, 264.

(30) Schreier, S.; Polnaszek, C. F.; Smith, I. C. P. Biochim. Biophys. Acta 1978, 515, 375 .

(31) Mellan, I. Industrial Solvents Handbook; Noyes: Park Ridge, NJ, 1970 